\title{
Efeito de Surfatantes e Pontas de Pulverização na Deposição de Calda de Pulverização em Plantas de Grama-Seda ${ }^{1}$
}

\author{
Effect of Surfactants and Nozzle Design on Spray Solution Deposition over \\ Cynodon dactylon Plants
}

CARBONARI, C.A. ${ }^{2}$, MARTINS, D. ${ }^{3}$, MARCHI, S.R. ${ }^{4}$ e CARDOSO, L.R. ${ }^{4}$

\begin{abstract}
RESUMO - O objetivo deste trabalho foi avaliar os efeitos de surfatantes e pontas de pulverização na deposição da calda de pulverização em plantas de Cynodon dactylon. Os tratamentos foram dispostos em um esquema fatorial $2 \times 5$, sendo duas pontas de pulverização (XR 11002 e TX-VK 8) e cinco caldas de pulverização (sem surfatante e com os surfatantes Aterbane e Silwet a $0,05 \%$ e $0,1 \%$ ). As caldas foram preparadas utilizando-se o corante FDC-1 a 1.500 ppm como traçador. O delineamento experimental foi o inteiramente casualizado, com 10 repetições. As aplicações foram realizadas através de um pulverizador estacionário a pressão constante e com consumo de calda de $150 \mathrm{~L} \mathrm{ha}^{-1}$. A ponta de pulverização do tipo jato cônico vazio proporcionou maior deposição nas folhas de gramaseda, quando comparada com a ponta do tipo jato plano, independentemente do adjuvante utilizado. As maiores deposições ocorreram nas doses de 0,1\%, para ambos os surfatantes, quando utilizada a ponta de jato plano e para o Silwet a $0,05 \%$ pulverizado com a ponta de jato cônico. A deposição de calda nas folhas foi menor quando da não-adição de surfatante, independentemente da ponta de pulverização utilizada.
\end{abstract}

Palavras-chave: adjuvante, gota, Cynodon dactylon, planta daninha.

\begin{abstract}
The objective of this trial was to evaluate the effect of surfactants and nozzle types on spray deposition over Cynodon dactylon plants. The treatments were arranged in a $2 \times 5$ factorial design, as follows: two nozzles (XR 11002 and TX-VK 8) and five spray solution conditions (Aterbane and Silwet at $0.05 \%$ and $0.1 \%$, and without surfactant). The spray solution was prepared using brilliant blue FDC-1 at 1,500 ppm as a tracer. The trial treatments were set up on a randomized design with 10 replications. The applications were performed with stationary spray equipment in a constant pressure so as to obtain a spray solution consumption of $150 \mathrm{~L} \mathrm{ha}^{-1}$. Nozzle TX-VK 8 provided a higher drop deposition compared with the flat fan nozzle, regardless of solution condition. Both Aterbane and Silwet at $0.1 \%$ provided increases in drop deposition with the solution applied with the flat fan nozzle. The highest drop deposition was observed when Silwet was applied at $0.05 \%$ through the hollow cone nozzle. Drop deposition on the leaves was more reduced for both nozzles when the solution was applied without surfactant.
\end{abstract}

Key words: surfactant, drop, Cynodon dactylon, weed.

Recebido para publicação em 29/3/2005 e na forma revisada em 25/11/2005.

2 Eng.-Agr., aluno do curso de Pós-Graduação em Proteção de Plantas em nível de Mestrado, Departamento de Produção Vegetal da FCA-UNESP, Caixa postal 237, 18603-970 Botucatu-SP, <carbonari@ fca.unesp.br>; ${ }^{3}$ Professor Livre Docente, Departamento de Produção Vegetal da FCA-UNESP; ${ }^{4}$ Eng.-Agr., aluno do curso de Pós-Graduação em Agricultura em nível de Doutorado, Departamento de Produção Vegetal da FCA-UNESP. 


\section{INTRODUÇÃO}

Cynodon dactylon é uma planta daninha popularmente conhecida por grama-seda, com ampla distribuição nas regiões tropicais e subtropicais no mundo. No Brasil, é encontrada em todo o território como planta ruderal, como infestante ou como cultivada.

Trata-se de uma das mais importantes gramíneas invasoras, devido à grande dificuldade em erradicá-la após o seu estabelecimento. É um problema tradicional em diversas culturas, dentre as quais se destaca a canade-açúcar, em que uma alta infestação pode reduzir em até $80 \%$ a produção, além de diminuir o número de cortes e a vida útil do canavial (Kissmann, 1997).

Têm-se observado em campo inúmeras falhas no controle químico desta espécie, as quais podem estar relacionadas a erros na aplicação dos produtos: a calda pulverizada pode não estar atingindo as plantas de forma adequada, com uma boa deposição das gotas sobre suas folhas.

Durante a pulverização de um herbicida ou de outros defensivos agrícolas, parte da quantidade aplicada não atinge o alvo desejado. Dessa forma, o aumento no custo desses produtos, da mão-de-obra e de energia despendida e a preocupação cada vez mais crescente em relação à poluição ambiental têm realçado a necessidade de uma tecnologia mais acurada para colocação do produto químico no alvo (Matuo, 1998). Segundo Cooke \& Hislop (1993), o conhecimento do destino dos produtos fitossanitários após sua aplicação é essencial no seu entendimento e estudo da eficiência em qualquer técnica de aplicação.

A qualidade da pulverização é um fator primordial para uma correta utilização de herbicidas. Assim, o uso de compostos denominados adjuvantes - os quais têm por finalidade promover alterações na calda de pulverização, possibilitando minimizar os efeitos ambientais e individuais de cada espécie e que possam comprometer a eficiência de um herbicida torna-se uma prática recomendável. De acordo com Miller \& Butler Ellis (2000), essas mudanças nas propriedades do líquido pulverizado podem influenciar tanto o processo de formação das gotas como o comportamento destas em contato com o alvo.

Planta Daninha, Viçosa-MG, v. 23, n. 4, p. 725-729, 2005
A escolha do tipo de ponta de pulverização também afeta a deposição das gotas pulverizadas sobre as plantas; para Galli \& Arruda (1985) e Bauer \& Raetano (2004), a uniformidade de cobertura da pulverização e o tamanho das gotas são fatores que dependem do desempenho do órgão emissor de gotas, que, no caso dos pulverizadores, é o bico pulverizador, considerado a parte mais importante do equipamento.

As avaliações dos depósitos são utilizadas nas pesquisas de tecnologia de aplicação como instrumento para desenvolver e melhorar as técnicas de aplicação de defensivos (Palladini, 2000). A avaliação de uma pulverização pode ser realizada através de um estudo da deposição de gotas sobre superfícies-alvo, que podem ser naturais ou artificiais. Há vantagens e desvantagens quanto ao tipo de alvo a ser utilizado; contudo, as superfícies naturais são mais recomendadas, por representarem melhor as condições reais de uma aplicação (Miller, 1993).

Dessa forma, o objetivo deste trabalho foi avaliar os efeitos de surfatantes e pontas de pulverização na deposição da calda de pulverização em plantas de C. dactylon.

\section{MATERIAL E MÉTODOS}

O experimento foi instalado e conduzido no Núcleo de Pesquisas Avançadas em Matologia - NUPAM, pertencente ao Departamento de Produção Vegetal da Faculdade de Ciências Agronômicas/UNESP, campus de Botucatu/SP.

As plantas de grama-seda foram cultivadas em vasos de $15 \mathrm{~L}$, em casa de vegetação, e a aplicação foi feita quando as plantas estavam em pleno desenvolvimento vegetativo, cobrindo toda a área do vaso e apresentando grande massa foliar.

Como tratamentos, utilizaram-se cinco caldas de pulverização, sendo elas acrescidas dos surfatantes Aterbane e Silwet L77 nas concentrações de 0,05 e $0,1 \% \mathrm{v} / \mathrm{v}$, além de uma calda sem adição de surfatante e duas pontas de pulverização, XR 11002VS e TX-VK 8, respectivamente, utilizadas em pressão de trabalho de $1,3 \mathrm{kgf} \mathrm{cm}^{-2}$ e 3,8 $\mathrm{kgf} \mathrm{cm}^{-2}$. As cinco caldas de pulverização foram preparadas colocando-se 1,5 grama de corante Azul Brilhante 
(FDC-1) por litro de água destilada, o que equivale à concentração de $1.500 \mathrm{ppm}$. Segundo Palladini (2000), esse corante não influi nas características físicas da calda, podendo ser utilizado como traçador para simulação de uma aplicação de herbicidas.

A aplicação foi realizada através de pulverizador estacionário pressurizado a ar comprimido com pressão constante, em sala fechada, equipado com barra de pulverização posicionada a $0,5 \mathrm{~m}$ de altura das plantas e munida de quatro pontas de pulverização, com espaçamento de 0,5 m entre bicos. A barra de pulverização foi deslocada à velocidade de $1 \mathrm{~m} \mathrm{~s}^{-1}$, proporcionando um consumo de calda de $150 \mathrm{~L} \mathrm{ha}^{-1}$ para todos os tratamentos. Foram colocadas quatro lâminas de vidro sobre o solo, nos vasos contendo as plantas de grama-seda, determinando-se a deposição de calda de pulverização no solo para os diferentes tratamentos. Durante a aplicação, as temperaturas máxima e mínima registradas foram de 19,9 e $19,4{ }^{\circ} \mathrm{C}$, respectivamente, e a umidade relativa do ar variou de 76 a $85 \%$.

Após a aplicação foram coletadas 10 amostras de 20 folhas de grama-seda por vaso, as quais foram retiradas aleatoriamente em todas as partes das plantas. As folhas amostradas foram lavadas imediatamente após a coleta, utilizando-se $15 \mathrm{ml}$ de água destilada para extração do corante retido na superfície foliar, constituindo assim as amostras para análise; o mesmo procedimento foi adotado na lavagem das lâminas, sendo cada uma lavada individualmente. A quantificação do corante presente nas amostras foi feita por meio de leitura em espectrofotômetro (GBC Cintra 40), determinando-se a absorbância no comprimento de onda de $630 \mathrm{~nm}$.

Os dados de absorbância foram transformados em dados de volume ( $\mathrm{mL}$ de calda $\mathrm{cm}^{-2}$ ), conforme Negrisoli et al. (2002). O delineamento estatístico foi o inteiramente casualizado, disposto em esquema fatorial $2 \times 5$, com 10 repetições. Os dados foram submetidos à análise de variância pelo teste $\mathrm{F}$ e as médias comparadas pelo teste $\mathrm{t}$ em nivel de $5 \%$ de probabilidade.

\section{RESULTADOS E DISCUSSÃO}

$\mathrm{Na}$ Tabela 1 estão apresentados os volumes de calda depositados sobre as plantas de grama-seda em função da ponta de pulverização e dos surfatantes. Para a variável surfatante, observa-se que para a ponta do tipo jato plano (XR 11002) o maior depósito da calda de pulverização ocorreu quando esta foi acrescida dos surfatantes Aterbane e Silwet a $0,1 \%$.

Tabela 1 - Volume de calda de pulverização $\left(\mu \mathrm{L} \mathrm{cm}^{-2}\right.$ de folha) depositado sobre plantas de grama-seda em função da ponta de pulverização e do surfatante

\begin{tabular}{|c|c|c|c|}
\hline \multirow{2}{*}{ Surfatante } & \multirow{2}{*}{$\begin{array}{c}\text { Concentração } \\
(\%)\end{array}$} & \multicolumn{2}{|c|}{ Pontas de Pulverização } \\
\hline & & XR 11002VS & TX-VK 8 \\
\hline Aterbane & 0,05 & $0,2075 \mathrm{C} \mathrm{b}$ & $0,2469 \mathrm{C} \mathrm{a}$ \\
\hline Aterbane & 0,1 & $0,2501 \mathrm{AB} b$ & $0,2886 \mathrm{~B}$ a \\
\hline Silwet L77 & 0,05 & $0,2289 \mathrm{BC} \mathrm{b}$ & $0,3528 \mathrm{~A} \mathrm{a}$ \\
\hline Silwet L77 & 0,1 & $0,2704 \mathrm{~A} \mathrm{a}$ & $0,2992 \mathrm{~B} \mathrm{a}$ \\
\hline sem adjuvante & - & $0,0686 \mathrm{D}$ a & $0,0941 \mathrm{D}$ a \\
\hline \multicolumn{2}{|c|}{ Pontas (P) } & \multicolumn{2}{|c|}{$39,63 * *$} \\
\hline \multicolumn{2}{|c|}{ Surfatantes (S) } & \multicolumn{2}{|c|}{$91,71^{* *}$} \\
\hline \multicolumn{2}{|l|}{$\mathrm{P} * \mathrm{~S}$} & \multicolumn{2}{|c|}{$5,10 * *$} \\
\hline \multicolumn{2}{|c|}{$\mathrm{CV}(\%)$} & \multicolumn{2}{|c|}{17,63} \\
\hline \multicolumn{2}{|l|}{ DMS } & \multicolumn{2}{|c|}{0,0361} \\
\hline
\end{tabular}

Médias seguidas de mesma letra maiúscula na coluna e minúscula na linha não diferem estatisticamente entre si pelo teste $\mathrm{t}(\mathrm{P}<0,05)$.

** valor significativo pelo teste $\mathrm{F}(\mathrm{P}<0,01)$.

Os adjuvantes Silwet e Aterbane a $0,05 \%$ também promoveram um bom volume de calda depositado sobre as plantas de grama-seda. Ainda, para a ponta do tipo jato plano, quando a calda não foi acrescida de adjuvantes, o depósito de calda nas plantas foi bastante reduzido em relação aos tratamentos em que houve acréscimo de adjuvantes. Essa redução alcançou $75 \%$, se comparada ao depósito máximo proporcionado pelo Silwet a $0,1 \%$.

Para a ponta de jato cônico vazio (TX-VK 8), a adição do adjuvante Silwet a 0,05\% à calda foi a que resultou no maior volume depositado sobre as folhas; no entanto, os adjuvantes Aterbane e Silwet a 0,1\% também proporcionaram bom depósito de calda. O Silwet a 0,1\% promoveu menor quantidade de calda sobre as folhas quando comparado à concentração de 0,05\%, provavelmente em função de escorrimento causado pelo grande volume depositado e pela baixa tensão superficial da calda 
decorrente da atuação deste adjuvante (Mendonça, 1999). Novamente, quando a calda não foi adicionada de adjuvante, a quantidade depositada sobre as folhas foi muito reduzida. Essa redução foi da ordem de $73 \%$, se comparada ao depósito máximo causado pelo Silwet a $0,05 \%$ para a ponta com jato cônico vazio.

Essas reduções na deposição observadas na aplicação da calda sem adjuvante indicam que a quantidade de herbicida retido nas folhas de grama-seda poderia não ser suficiente para provocar a morte das plantas; além disso, as perdas de produtos para o ambiente são grandes, aumentando a sua contaminação.

Pode-se observar, para a variável ponta de pulverização, que as pontas do tipo jato cônico vazio (TX-VK 8) promoveram maior depósito da calda sobre as plantas, quando esta foi acrescida de Aterbane em ambas as doses e Silwet a 0,05\%. Observa-se também maior deposição para as pontas de jato cônico nas lâminas colocadas no solo, conforme Tabela 2. Embora não tenham diferido estatisticamente, observa-se que uma maior quantidade de calda atingiu o solo para a ponta do tipo jato cônico, em relação à ponta de jato plano. Esses resultados corroboram os obtidos por Maciel et al. (2000), que também observaram deposição maior e mais uniforme em pulverizações em Brachiaria decumbens com pontas do tipo cônico (TX-VK 8), em relação ao jato plano (XR 11002). As caldas

Tabela 2 - Volume de calda de pulverização $\left(\mathrm{L} \mathrm{ha}^{-1}\right)$ depositado sobre lâminas na altura do solo durante a aplicação nas plantas de grama-seda, em função da ponta de pulverização e do surfatante

\begin{tabular}{|c|c|c|c|}
\hline \multirow{2}{*}{ Surfatante } & \multirow{2}{*}{$\begin{array}{c}\text { Concentração } \\
(\%)\end{array}$} & \multicolumn{2}{|c|}{ Pontas de Pulverização } \\
\hline & & XR 11002VS & TX-VK 8 \\
\hline Aterbane & 0,05 & 142 & 161 \\
\hline Aterbane & 0,1 & 144 & 167 \\
\hline Silwet L77 & 0,05 & 137 & 163 \\
\hline Silwet L77 & 0,1 & 142 & 164 \\
\hline sem adjuvante & - & 137 & 160 \\
\hline \multicolumn{2}{|c|}{ Pontas (P) } & \multicolumn{2}{|c|}{$14,330 * *$} \\
\hline \multicolumn{2}{|c|}{ Surfatantes $(\mathrm{S})$} & \multicolumn{2}{|c|}{$0,172^{\mathrm{ns}}$} \\
\hline \multicolumn{2}{|l|}{$\mathrm{P} * \mathrm{~S}$} & \multicolumn{2}{|c|}{$0,038^{\mathrm{ns}}$} \\
\hline \multicolumn{2}{|c|}{$\mathrm{CV}(\%)$} & \multicolumn{2}{|c|}{12,70} \\
\hline \multicolumn{2}{|l|}{ DMS } & \multicolumn{2}{|c|}{27,80} \\
\hline
\end{tabular}

** valor significativo pelo teste $\mathrm{F}(\mathrm{P}<0,01)$.

Planta Daninha, Viçosa-MG, v. 23, n. 4, p. 725-729, 2005 sem adjuvantes e acrescidas de Silwet a 0,1\% apresentaram depósitos semelhantes nas folhas de grama-seda para as duas pontas de pulverização testadas.

Também Scudeler (2004), estudando a influência de ponta de pulverização na deposição de calda sobre a cultura da batata, concluiu que a ponta de jato cônico (JA-4) promoveu maior depósito de calda no baixeiro das plantas, em relação à ponta de jato leque (AVI1 1004); contudo, na parte superior das plantas as duas pontas comportaram-se de maneira semelhante. Silva (2000) também avaliou o efeito de diferentes pontas de pulverização na deposição de calda de pulverização sobre plantas de Cyperus rotundus, sendo elas do tipo jato plano (XR 11002VS e DG 11002VS), jato plano duplo (TJ 60 110.02VS) e jato cônico (TXVS-4 e FL-5 VS), e concluiu que as pontas de jato plano do tipo DG e XR apresentaram maiores depósitos, sendo estes de 5,25 e 54,65\%, respectivamente, o que demonstrou que a deposição está relacionada não somente à ponta de pulverização, mas também às características de cada espécie, além das demais condições de aplicação.

De maneira geral, a ponta de pulverização do tipo jato cônico vazio proporcionou maior deposição nas folhas de grama-seda; para a ponta do tipo jato plano, os adjuvantes Silwet e Aterbane nas concentrações de $0,1 \%$ promoveram a maior deposição de calda nas plantas. Para a ponta do tipo jato cônico, a maior deposição de calda foi proporcionada pelo adjuvante Silwet a $0,05 \%$. A deposição nas folhas foi reduzida para a calda sem adição de surfatante, independentemente das pontas de pulverização.

\section{LITERATURA CITADA}

BAUER, F. C.; RAETANO, C. G. Distribuição volumétrica de calda produzida pelas pontas de pulverização XR, TP e TJ sob diferentes condições operacionais. Planta Daninha, v. 22, n. 2, p. 275-284, 2004.

COOKE, B. K.; HISLOP, E. C. Spray tracing techniques. In: MATHEWS, G. A.; HISLOP, E. C. Application technology for crop protection. Trowbridge: CAB INTERNACIONAL, 1993. p. $85-100$.

KISSMANN, K. G. Plantas infestantes e nocivas. São Paulo: Basf, 1997. Tomo 1. 825 p. 
MACIEL, C. D. G. et al. Avaliação do depósito e distribuição de calda de pulverização em plantas de feijoeiro e Brachiaria decumbens. In: CONGRESSO BRASILEIRO DA CIÊNCIA DAS PLANTAS DANINHAS, 22., 2000, Foz do Iguaçu. Resumos... Foz do Iguaçu: SBCPD, 2000. p. 472.

GALLI, J. C.; ARRUDA, A. C. Distribuição volumétrica dos bicos pulverizadores JD14-2. Pesq. Agropec. Bras., v. 20, n. 11, p. 1239-1244, 1985.

MATUO, T. Fundamentos da tecnologia de aplicação de agrotóxicos. In: GUEDES, J. V. C.; DORNELLES, S. H. B. (Eds.) Tecnologia e segurança na aplicação de agrotóxicos: novas tecnologias, Santa Maria: Sociedade de Agronomia de Santa Maria, 1998. p. 95-103.

MENDONÇA, C. G. et al. Efeitos de surfatantes sobre a tensão superficial e área de molhamento de soluções de glyphosate sobre folhas de tiririca. Planta Daninha, v. 17, n. 3, p. 355-366, 1999.

MILLER, P.C.H. Spray drift and its measurement. In: MATTHEWS, G. A.; HISLOP, E. C. Application technology for crop protection. Trowbridge: $\mathrm{CAB}$ International, 1993. p. 101-122.
MILLER, P. C. H.; BUTLER ELLIS, M. C. Effects of formulation on spray nozzle performance for applications from ground-based boom sprayers. Crop Protec., v. 19, p. 609-615, 2000.

NEGRISOLI, E. et al. Depósitos unitários de calda de pulverização com e sem surfatante em plantas de Salvinia molesta. Planta Daninha, v. 20, p. 51-56, 2002. Edição Especial.

PALLADINI, L. A. Metodología para a avaliação da deposição em pulverização. Botucatu, Universidade Estadual Paulista, 2000. 111 p. Tese (Doutorado em Agronomia/Proteção de Plantas) - Universidade Estadual Paulista, Botucatu, 2000.

SUDELER, F.; FUGIKAWA, L. H.; RAETANO, C. G. Influência do tipo de ponta de pulverização e do volume de aplicação na deposição do traçador cobre na cultura da batata (Solanum tuberosum L.). In: SIMPÓSIO INTERNACIONAL DE TECNOLOGIA DE APLICAÇÃO DE AGROTÓXICOS, 3., 2004, Botucatu. Resumos... Botucatu: 2004. p. 179-181. 